\title{
Editorial
}

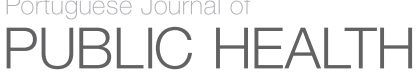

\section{Thinking Ahead: Portugal's Health in 2027}

\author{
Alexandre Abrantes $^{a} \quad$ Jorge Simões ${ }^{b}$ \\ ${ }^{a}$ Department of Health Policy and Management, CISP - Public Health Research Center, National School of \\ Public Health, NOVA University of Lisbon, Lisbon, Portugal; ${ }^{b}$ International Public Health and Biostatistics Unit, \\ Global Health and Tropical Medicine, Institute of Hygiene and Tropical Medicine, NOVA University of Lisbon, \\ Lisbon, Portugal
}

\section{Keywords}

National health service $\cdot$ Health strategy $\cdot$ Health policy . Health care management

\section{Pensar a Saúde para 2027}

\section{Palavras chave}

Serviço nacional de saúde - Estratégia para a saúde ·

Políticas de saúde · Gestâo de organizações de saúde

The discussion on a health strategy for Portugal has been centered on financial issues, namely on the shortterm economic and financial sustainability of the National Health Service (NHS). This approach does not offer an outlook for the future and does not address the main health issues the Portuguese will have to face. These can only be tackled in a sustainable way with a series of longand medium-term interventions that address the issues identified by patients, health-care providers, and health services in general.

One can understand the focus on financial issues given that budget constraints have clearly limited the develop- ment of the public side of the health systems and that there cannot be quality services without adequate funding. This short-term, strictly economic and financial approach cannot respond to the challenges the NHS is facing, namely those related to multiple morbidities of an aging population, the rhythm of innovation in the health sector, and the impact of globalization on the health of the Portuguese and the NHS, specifically through the free movement of capital, technology, people, knowledge, and culture.

The needs of the patients and other users must be central in the health strategy. On the other hand, issues related to health-care providers must be taken seriously because health-care providers are those who are responsible for treating and caring for patients on the front line and because their clinical decisions determine most health expenditures. Finally, issues presented by health-care managers must be carefully considered because health-care managers are responsible for the mediation between those who finance and provide health care and are ultimately responsible for an effective and efficient use of health-care resources.

We suggest that, looking ahead to the next decade, health policies will have to address 4 problems with clear and rapid action.

\section{KARGER}

E-Mail karger@karger.com www.karger.com/pjp
(C) 2018 The Author(s). Published by S. Karger AG, Basel on behalf of Escola Nacional de Saúde Públic

Karger

$\checkmark$ pen access

This article is licensed under the Creative Commons AttributionNonCommercial-NoDerivatives 4.0 International License (CC BYNC-ND) (http://www.karger.com/Services/OpenAccessLicense) Usage and distribution for commercial purposes as well as any distribution of modified material requires written permission.
Alexandre Abrantes

Department of Health Policy and Management, CISP - Public Health Research Center National School of Public Health, NOVA University of Lisbon

Av Padre Cruz, PT-1600-580 Lisbon (Portugal)

E-Mail aabrantes@ensp.unl.pt 


\section{Problem 1}

If we listen to what NHS patients have to say, we will learn that many experience barriers in accessing the NHS: (a) many beneficiaries cannot enroll on the list of NHS family doctors; (b) a large proportion of patients who seek a health center end up being referred to other units, private or public, because health centers are not staffed or equipped to operate as a "one-stop shop"; (c) patients who need specialized care or elective surgery face long waiting lists in the public health system and are, therefore, forced to use the private sector, with significant out-ofpocket costs; and, finally, (d) families bear a disproportionate financial strain when purchasing drugs, dental and eye care, and other specialized tests and consultations that are not easily accessible in the public service.

On the primary care side, in 2015, 1.1 million beneficiaries of the NHS could not enroll on a family doctor list. The situation has improved since but, in 2017, the problem persisted for over 850 thousand beneficiaries of the NHS. On the hospitals' side, the mean waiting time for a specialty consultation is 120.5 days, in 2016 , but it can be, for example, more than 500 days for dermatology consultation in the hospitals of Almada, Leiria, Aveiro, Viseu, Gaia, and Vila Real. Finally, in 2016, families paid $27 \%$ of health expenditures, much more than the average of $14 \%$ in the EU countries [1].

Portugal has a reasonable number of physicians, nurses, and other allied health professionals when compared to other EU countries. But they are poorly distributed geographically and by specialty. This distorted distribution creates equity issues across the country and inefficiencies in the national health system.

Moreover, the system for scheduling consultations, ancillary tests, management of hospital beds, surgeries, and discharges is based on a structural approach to serve the needs of professionals instead of focusing on patient convenience.

\section{Proposals}

(a) Equip and staff primary health-care centers in view of making them into "one-stop shops" with ancillary diagnostic and therapeutic service capacity and some specialized care providers, to avoid frequent referrals and bypasses towards hospital outpatient and emergency care services.

(b) Create a nationally integrated and operational IT platform for the scheduling and management of consultations, ancillary diagnostic and therapeutic services, hospital admissions and bed occupancy, and surgical inter- ventions to reduce waiting times and allow for patient choice; despite piecemeal attempts to develop such prototypes, they have not been integrated and do not operate coherently, effectively, and efficiently in the NHS.

(c) Develop an organizational change program to put patient needs and satisfaction at the center of the NHS.

\section{Problem 2}

If we listen to what health-care professionals have to say, we will hear about great dissatisfaction with the NHS organizational climate. Health-care professionals complain of low pay, long hours, nonclinical administrative overload, burnout, and few opportunities for professional and career development. No wonder the NHS has seen a significant migration of its staff. The Order of Physicians stated recently that, in 2016, 600 MDs requested documentation for emigrating, a 30\% increase compared to 2015. On the nursing side, the Order of Nursing has registered an increasing number of requests from nurses wanting to work abroad, from 179 in 2010 to around 2,700 per year between 2012 and 2015! The national health system and the NHS need some level of social peace so that professionals can focus their energies on caring for patients.

The education and training of doctors, nurses, and other allied health-care professions has improved tremendously over the past few decades, providing them with broad and deep knowledge and skills. Yet, the boundaries of the respective clinical work remain almost unchanged. The health system relies heavily on an expensive model based on the medical practitioners, while other well-trained nurses and allied health professionals, who could do so much more, remain underrecognized and underutilized. This situation is particularly visible at the level of primary health care, but also at other technical levels for which these nonmedical health professionals are well prepared.

\section{Proposals}

(a) Review and make more flexible the management of human resources to recruit and retain professionals where they are needed.

(b) Acknowledge the specificity and relevance of the allied health professions, adjusting the respective job descriptions in accordance with their education and training to maximize their technical input to the health-care team in a more collaborative health-care delivery model involving the patients. 
(c) Review the compensation package and incentives for health professionals to improve the organizational climate in the NHS.

These proposals are particularly important because the need for human resources in the health sector must take into consideration changes in the demographic and epidemiologic profiles, the changing demand for health care, the organization of the health system, but also changes in the job profile of different health professionals, including the boundaries between different professions and specializations.

\section{Problem 3}

If we listen to what health-care administrators and managers have to say, we will hear that health planning has lost status in the Ministry of Health $(\mathrm{MoH})$. For many years, the MoH had a prestige Department of Studies and Planning (DEPS) that carried out research on the operation of the health system and conducted comprehensive planning for infrastructure, human resources, etc. Its reports were highly valued and guided, for many years, the medium- and long-term development of the health system. Unfortunately, the DEPS was extinct in 1997 (Decreto-Lei 122/97/), and its functions were diluted in different units in the $\mathrm{MoH}$. Since then, the $\mathrm{MoH}$ has rarely produced reports or white papers of equivalent significance. To compensate for lack of in-house thinking and planning, the $\mathrm{MoH}$ has relied on external consultants and ad hoc policy notes. No wonder that many such "wannabe" planning exercises go up in smoke for a lack of institutional ownership. Because politicians lack the support of medium-term thinking and planning, they are often led to taking decisions on the spot, without sufficient buy-in, and many of these decisions are announced but never implemented.

It is wrong to ignore the memory of the public health administration. The institutional memory is essential for keeping and sharing the studies that led to major policy options and decisions, such as the creation of a national network of primary health-care centers, new hospitals and multiple hospital centers, public-private partnerships, local health units, and long-term care networks. This institutional memory is essential to create ownership not only in the incumbent Government, but also in those Governments to come. Weak planning has had a negative impact on the quality of decisions to build, or not build, several hospitals over the past few years.

Thinking Ahead: Portugal's Health in 2027
More so, Governments have granted financial and administrative autonomy to hospitals and regional healthcare administrations but, in practice, have violated the performance contracts on which this autonomy was based and have directly interfered with the management of those agencies, undermining the principles of responsibility and accountability on which the system should rely.

\section{Proposal}

(a) Reestablish at the $\mathrm{MoH}$ the planning structures and routines providing transparent, accountable, verifiable, sound, and legitimate decisions shared by large strata of society; this should be the instance responsible for establishing the evidence on the need for building new hospitals or other health-care facilities, on the respective locations, dimensions, and type, or on whether other priorities, such as primary or long-term care, should be considered. This ongoing technical assistance is essential for taking wise political decisions. All these technical papers should be public to ensure transparency.

(b) Empower health-care managers, in hospitals and regional health-care administrations, to manage their agencies according to the performance contracts signed with the central NHS administration. We need to combat the centralizing temptation of the $\mathrm{MoH}$, not only to respect the Constitution, which states that "the National Health Service has a decentralized and participative management ...," but also to improve the technical efficiency of the system.

\section{Problem 4}

Life expectancy of the Portuguese, at age 65 years, is 19 years, which is lower than it could be. In 2015, life expectancy of the Portuguese at birth was 81.3 years, in line with the EU average of 80.6 years. But life expectancy at age 65 years was 1-2 years lower in Portugal than in other European countries, such as Malta, Italy, Luxembourg, Spain, and France [1]. Why would that be? Most likely because, over the years, we may not have had the appropriate health care we needed, because our lifestyle (nutrition, physical exercise, alcohol, and tobacco consumption, etc.) may not have been healthy. On the other hand, the support provided by social services to the aging population, ever more dependent and isolated, is still very limited, shifting to the NHS the burden of providing many social services which were not included into its original mission, and, therefore, the system does not deliver in a very effective or efficient way. 


\section{Proposal}

Create an integrated health promotion program, involving different ministries and social partnerships, to ensure the joint engagement and accountability of both state and society. Such a program should engage schools, workplaces, local authorities, agriculture and territorial development, economy, and finance. This program could take a stepwise approach but should be based on a wellknown and legitimized strategy. Health should permeate all policies and cease being just a piece of rhetoric, to become an integrated strategy.
1 De Almeida Simões J, Augusto GF, Fronteira I, Hernandez-Quevedo C: Portugal: Health System Review. European Observatory on Health Systems and Policies. Health Syst Transit 2017;19:1-184. 